\title{
Organocatalyzed Asymmetric Michael Addition of Ketones and Nitrostyrenes
}
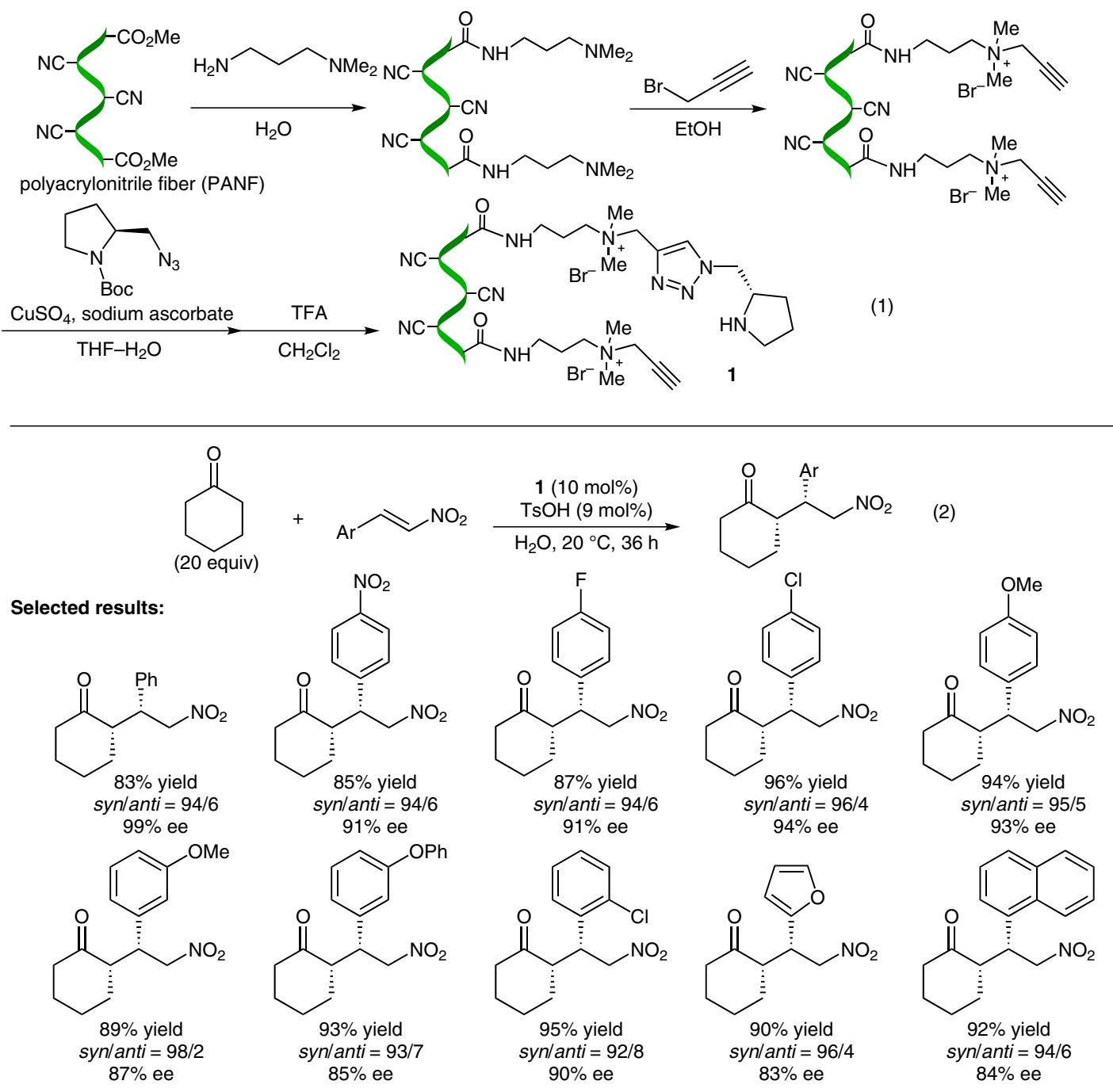

Significance: The polyacrylonitrile-fiber-supported chiral pyrrolidine catalyst $\mathbf{1}$, prepared as shown in eq. 1, promoted the asymmetric Michael addition of cyclohexanone to trans- $\beta$-nitrostyrenes in water to give the corresponding Michael adducts in $83-96 \%$ yield, a syn/anti ratio of 92:8 to $98: 2$, and $83-99 \%$ ee (eq. 2; 11 examples).

SYNFACTS Contributors: Yasuhiro Uozumi, Shuichi Hirata Synfacts 2016, 12(08), 0867 Published online: 19.07.2016 DoI: 10.1055/s-0035-1562400; Reg-No.: Y08116SF

\section{Category}

Polymer-Supported Synthesis

\section{Key words}

organocatalysis

asymmetric catalysis

Michael addition

nitrostyrenes

ketones

Comment: Catalyst $\mathbf{1}$ was characterized by FTIR, SEM, and elemental analyses. When a silica column packed with catalyst $\mathbf{1}$ was used in a flow reaction of cyclohexanone with [(E)-2-nitrovinyl]benzene, its catalytic performance was comparable with those observed in the batch reaction. The column-packed catalyst was reused three times without significant loss of its catalytic activity (fresh: 68\% yield, syn/anti $=97: 3,99 \%$ ee; third reuse: $63 \%$ yield, syn/anti $=95: 5,99 \%$ ee). 